\title{
El espacio público entre la asfixia y la resistencia: usos de Foucault durante la dictadura argentina
}

\author{
Mariana Canavese \\ CONICET, Buenos Aires, Argentina. Email: mcanavese@gmail.com
}

\begin{abstract}
Resumen: Aunque las primeras lecturas y apropiaciones de textos de Michel Foucault en Argentina datan de fines de la década de 1950, nos interesa aquí detenernos en algunas de las formas de circulación, lectura, interpretación y apropiación de las elaboraciones foucaultianas bajo las condiciones impuestas por la última dictadura militar argentina. Esta propuesta tiene, entonces, como objetivo principal reconstruir históricamente y analizar algunas de esas apropiaciones que, entre fines de la década de 1970 y principios de los '80, se manifestaron en las Ciencias Sociales, en debates académicos y en producciones relacionadas con problemáticas locales, bajo la hipótesis de que es posible divisar la vitalidad de un espacio público subterráneo que subsistió aun en las peores condiciones de opresión. Tomar algunos de estos casos nos permitirá explorar usos estratégicos en el ámbito político-intelectual que ampliaban los márgenes de un espacio público sofocado.
\end{abstract}

Palabras clave: Recepción, Foucault, espacio público, dictadura, Argentina.

\section{Public space inbetween asphyxia and resistance: Foucault's uses during the dictatorship in Argentina}

\begin{abstract}
Although the first readings and appropriations of Michel Foucault's texts in Argentina date back to the end of the 1950s, this paper analyzes some forms of circulation, reading, interpretation and appropriation of Foucault's elaborations under the conditions imposed by Argentina's last military dictatorship. This paper's principal aim is then to historically rebuilt and analyze some of these appropriations which, between the end of the 1970s and the beginning of the 1980s, appeared within the Social Sciences, in academic debates and in works related to local problems. The hypothesis is that it is possible to see the vitality of an underground public space that survived even the worst conditions of oppression. Analyzing some of these cases, allows to explore strategic uses of Foucault's elaborations within the political-intellectual area, extending the margins of a suffocated public space.
\end{abstract}

Key words: Reception, Foucault, public space, dictatorship, Argentina.

\section{O espaço público entre a asfixia ea resistência: usos de Foucault durante a ditadura na Argentina}

Resumo: Embora as primeiras leituras e apropriações de textos de Michel Foucault na Argentina datam de fimes do 1950, nos interessa aqui de me debruçar sobre algumas das formas de movimento, leitura, interpretação e apropriação de elaborações foucaultianaa trabalhando sob as condições impostas pelo última ditadura militar da Argentina. Esta proposta te, então, como principal objetivo reconstruir historicamente e analisar algumas dessas dotações que, entre final de 1970 e início dos anos 80, foram observados nas ciências sociais nos debates acadêmicos e questões relacionadas à produção local sob a hipótese de que é possível ver a vitalidade de um espaço público subterrâneo que sobreviveu até mesmo nas piores condições de opressão. Tomar alguns destes casos nos permitirá explorar usos estratégicos nos âmbitos políticos e intelectuais que expandiram as margens do espaço público sufocado.

Palavras-chave: Recepção, Foucault, Espaço Público, Ditadura

$$
* * *
$$

El campo cultural argentino se transformó duramente en los años setenta. La censura se amplificó hacia 1976, cuando la cotidianidad de la violencia política, el malestar social, la crisis institucional y el descontrol económico abrazaron el golpe del 24 de marzo que instaló a la Junta Militar y dejó a su paso treinta mil desaparecidos. La represión se abalanzó con saña sobre las letras: en 1974 una bomba quemó 25 mil ejemplares del Marxismo de Henri Lefebvre; ese mismo año, una comisión formada por la Cámara Argentina del Libro, la Cámara Argentina de Editores de Libros y la Sociedad Argentina de Escritores, entre otros, hizo manifiesto que el conjunto de leyes y decretos vigentes perjudicaba a más de 500 libros de autores argentinos y extranjeros y a 237 empresas editoriales nacionales y del exterior; para la segunda mitad de la 
década, dentro de los objetivos de represión cultural del Ministerio del Interior entraban desde la sexualidad hasta Nietzsche, pasando por libros como Estructuralismo y psicoanálisis de Nueva Visión (Invernizzi 2002). Parafraseando a Oscar Terán, una discursividad nacionalista, autoritaria, antiliberal, heterofóbica y familiarista, la de la moral cristiana, la tradición y la "seguridad nacional", apuntó desde 1976 a sepultar otra discursividad laicizante, libertaria, modernista o marxista, todo aquello que cuestionase la familia argentina, el modo de ser occidental y cristiano, el orden y las jerarquías establecidas (Terán 2008: 297-300). Sería fácil inferir de lo anterior que las obras de Michel Foucault no podían ser admitidas dentro del marco dispuesto por la última dictadura militar para el redisciplinamiento social, que la asfixia interminable lo teñía todo.

En efecto, la industria editorial argentina, que había sido realmente próspera, se encontraba al terminar la década replegada, desnacionalizada y concentrada, expresada en más altos costos y menor tiraje promedio ${ }^{1}$, cantidad de librerías y de ediciones de obras teóricas. De lo que quedaba, entre marzo de 1976 y diciembre de 1982, sólo la Secretaría de Cultura de la Municipalidad de Buenos Aires impugnó 560 libros, 433 forzados al ocultamiento y 127 declarados inmorales. Para más, muchas editoriales empezaron a ver cara a cara su crisis; algunas, como el Centro Editor de América Latina, la quema de más de un millón de ejemplares; otras, la clausura, como en el caso de la filial argentina de la mexicana Siglo XXI en cuyo departamento quedaron tirados los títulos de Foucault, Barthes, Derrida, Lacan y otros (Invernizzi 2002)2.

Sin embargo, y pese incluso al poder de la autocensura, la producción y la circulación intelectuales prosiguieron, tanto a través de sus canales consagrados - ciertos institutos y centros de investigación, determinados autores o suplementos culturales-, como por medio de la resistencia que significó la publicación de revistas - como Punto de Vista desde marzo de 1978-, la emergencia de grupos de estudio y de editoriales donde Foucault aparecía. Al respecto, evocaba el crítico literario y editor Jorge Lafforgue: "Si el recuerdo no me traiciona -y mi recuerdo va de León Rozitchner y Oscar Masotta a Josefina Ludmer y Santiago Kovadloff-, los trabajos de Lacan, Foucault, Greimas, Bajtín, Derrida, Williams, Jauss y muchos otros, se conocieron antes, más y mejor en estos ámbitos privados o restringidos [cursos privados, talleres literarios, etcétera] que en las universidades, donde su recepción fue tardía" (Sosnowski, 1988: 159).

Por esta vía, estas páginas se centran en dilucidar la dinámica del espacio público, no cuando florece sino en momentos en que parecería agotarse, cuando no se lo ve nítidamente a la luz del día y persevera en prácticas tenues, a contramano de la imagen común que lo asocia indisolublemente a la existencia de un régimen democrático. Para ello el caso de Foucault es paradigmático. Si, por un lado, fue precisamente él quien afirmó que la resistencia no desaparece aun cuando nada indicaría su existencia, por el otro, en ese período dictatorial, que transcurrió entre la experiencia política de masas de los años 60 y comienzos de los '70 y la llegada de la democracia procedimental, ofició como una de las claves de lectura de la realidad social. Aun cuando las condiciones impuestas por la dictadura militar replegaran las más dilatadas posibilidades de la cita foucaultiana, la difusión de esas ideas se trama en esos años especialmente en su ponderación como historiador del castigo y el encierro y en su operatoria sobre núcleos conceptuales como "sujeto" y "poder".

Ciertamente, ¿qué pasaba ahora por las aduanas, pero también cómo afectaba el temor a editar ciertos autores? ¿Y cuáles fueron las artimañas de la circulación de los escritos? ¿Es posible distinguir transformaciones en aquellas lecturas entre el alivio inmediato con que buena parte de la población recibió un golpe que creía vendría a poner fin al desconcierto del gobierno de Isabelita y el intento de apertura política en 1981, y desde entonces hasta las elecciones abiertas de octubre de 1983? ¿Qué tipo de subjetividad apuntalaron, qué identidades contribuyeron a moldear, qué grietas abrieron en la percepción de los sujetos bajo un régimen dictatorial? ¿Qué relaciones tramaron entre la violencia y la represión a escala macro y las microresistencias que podían significar, por ejemplo, los grupos de estudio? ¿Cómo operó, no digamos ya el "autor" Foucault, sino las representaciones que podían agruparse bajo ese nombre, en el marco de un dispositivo de vigilancia y disciplinamiento de los cuerpos, de control de la producción y de la circulación de ideas? ¿Ciertos usos de Foucault acreditaron la crítica a la radicalización política? ¿Cómo se lo lee, en fin, desde la marginalidad de aquellos años? Estas y otras preguntas estimulan este trabajo que busca reconstruir históricamente y analizar algunas de las apropiaciones y de los usos de Foucault que se manifestaron entonces en las Ciencias Sociales y en producciones relacionadas con problemáticas que atravesaban el Cono Sur, explorando vías de circulación subterráneas pero también formas de lectura y grietas abiertas en el campo político-intelectual. 


\section{Circulación: el murmullo Foucault}

Hay que decir que, en contra de los diagnósticos rápidos que podrían hacerse sobre aquel momento y a sabiendas de que la dictadura condenó a los autores considerados sospechosos fuese por su apellido o por su procedencia, Foucault está presente en distintas publicaciones periódicas culturales del período, alimentando la discusión colectiva. Por ejemplo, tanto desde los primeros números de la revista de crítica cultural Punto de Vista - continuación de Los Libros- como en la literaria Sitio - publicada desde diciembre de 1981-. En la primera se codea, en la forma de la referencia, la cita o la traducción, con Martínez Estrada, el grupo Contorno o Tel Quel, Pierre Bourdieu y Raymond Williams, entre otros. Así, en la publicación que se origina con el propósito de ejercer "el derecho al punto de vista", de "reivindicar la libertad de pensar, escribir, difundir ideas diferentes", de disentir como "condición básica de la cultura, amenazada material y políticamente" (Punto de Vista 1981: 2) ${ }^{3}$, textos como Historia de la locura (Foucault, 1967) e Historia de la sexualidad: La voluntad de saber (Foucault, 1977) encuentran alusiones implícitas y explícitas, por ejemplo en las notas de Hugo Vezzetti sobre la locura en nuestro país ${ }^{4}$, o en comentarios específicos. Ya en 1978 se le dedica una reseña al primer tomo de Historia de la sexualidad. Allí se refiere también a Historia de la locura señalando la relación con el psicoanálisis (como herramienta contra la psiquiatría) pero buscando también restituir la crítica que Foucault le hace al mismo, en tanto mantendría la figura alienante del médico y el silenciamiento de la sinrazón; dicha confusión se disiparía en Historia de la sexualidad. Respecto de los vínculos entre ambos libros, en el último -se afirma- Foucault trataría de desentrañar los mecanismos por los cuales "la racionalidad psicoanalítica, su discurso sobre el deseo y la ley -enmascarando otra verdad, la del cuerpo y sus placeres- se hace cómplice de un dispositivo montado para la definitiva sujeción del hombre" (Mayer 1978: 16-17). Así, en la sociedad contemporánea la estrategia de poder sería, ya no reprimir, sino multiplicar los discursos sobre el sexo; esa voluntad de saber es condición para la producción de la sexualidad, a través de ella el cuerpo queda encadenado. Para la expansión de este dispositivo al cuerpo social "habrá que esperar al momento en que se entrecrucen dos objetivos de poder: la necesidad de disciplinar el cuerpo, adiestrarlo y distribuir sus fuerzas, y la de regular las poblaciones, en función de la productividad económica (...) Efecto del poder, la sexualidad funciona en el hombre como elemento alienante, de coacción (...) de allí que el psicoanálisis surja como el cómplice más sofisticado de un método de sometimiento. Si la racionalidad médica silenció la sinrazón bajo la máscara de la locura; la psicoanalítica, propone Foucault, paraliza el cuerpo, a través de su discurso sobre la ley y el deseo (...) Los planteos inaugurados en Historia de la locura adquieren aquí plena coherencia" (Ibid: 17).

Interesan, entonces, no sólo las correspondencias que se establecen entre los textos de Foucault, componiendo a través de ellas una suerte de cohesión de la "obra" foucaultiana, sino también tanto la claridad con que se señalan los obstáculos para una filiación entre Foucault y el psicoanálisis -identificación que ya se había hecho un lugar en Argentina durante los años precedentes-, como la exposición entonces y desde esta revista surgida en una situación de semi-clandestinidad de una lectura de Foucault atenta a la sujeción, a la lógica de disciplinamiento de los cuerpos y de regulación de las poblaciones. Por otra parte, las categorías foucaultianas aparecerán en comentarios breves. Es el caso, por ejemplo, de la noción de "dispositivo" y de la concepción productiva del poder (H.V. 1982). En esas páginas, Foucault figurará, finalmente, tanto en publicidades del mundo editorial ${ }^{5}$ como en traducciones del francés al castellano: En el número 17 se anuncia en tapa el "Debate: la historia discute a Michel Foucault", y enseguida se afirma que Vigilar y Castigar planteó a los historiadores cuestiones de método y de teoría que Michel Foucault les imponía desde fuera de la disciplina (...)”. El dossier incluye el texto de Jacques Léonard en el que critica Vigilar y Castigar al tiempo que atiende a sus sugerencias, y la respuesta de Foucault (Punto de Vista 1983: 22-34). Tenemos, pues, alusiones a Foucault, que van del psicoanálisis a la historia, en una de las revistas culturales más recordadas de la época, que empiezan a poner en cuestión los dispositivos de disciplinamiento.

En Sitio $^{6}$ las referencias alternan con menciones a Roland Barthes o a James Joyce, entre muchos otros. Foucault se hace presente allí en anuncios sobre la edición de La verdad y las formas jurídicas por Gedisa o en citas, por caso, de parte de dos de sus directores: Eduardo Grüner, mencionando Las palabras y las cosas para concluir que la literatura "arrastra todavía la hipoteca de la voluntas significandi medieval; como instrumento de cultura, no es un cuerpo textual, ni siquiera un conjunto de normas del bien escribir, sino una operación designativa que comienza con este tipo particular de signo que se llama littera, la letra. Y la letra escrita, material, no es más que la dimensión extrínseca, epidérmica, del sentido. Es, como dice Foucault, 
el sentido en exilio" (Grüner 1981: 13-20); Luis Gusmán, por su parte, en "Del destierro al exilio: versiones e inversiones", retomando de "Stultifera Navis", el primer capítulo de Historia de la locura, la reflexión de Foucault sobre el Narrenschiff (La nave de los locos), aquella obra de Sebastian Brant, como composición literaria inspirada en el ciclo de los Argonautas (Guzmán 1983: 69). Se trata de citas claramente literarias, pero que no dejan de contener entre líneas aspectos de la coyuntura política de aquellos años. Más aún, son revistas que agruparon a intelectuales de talla apenas comenzada la dictadura, situados en el borde entre lo que se podía enunciar y lo que no.

Empero, la aparición de Foucault excedió el mero campo experto, puesto que su presencia se hizo manifiesta también en las páginas de grandes diarios. Por ejemplo, y considerando también que la neutralización ganó en este período los suplementos culturales de la prensa en general, sus elaboraciones tenían espacio en La Opinión. El periódico fue intervenido desde 1977 y secuestrado ese año su director, Jacobo Timerman. Entre agosto de 1975 y julio de 1979, el suplemento cultural estuvo a cargo del escritor Luis Gregorich: “Aunque intervenido, La Opinión no se convirtió en un diario oficialista (...) Pude conservar -opinaba Gregorich- la orientación progresista y plural de sus colaboradores y contenidos. Era toda una ironía que el suplemento de un diario intervenido fuera el único en incluir ciertos nombres y en referirse a determinados temas" (Sosnowski 1988: 113-114). Ese suplemento recomendaba, como lectura para el verano del '78, Historia de la sexualidad.

Desde este renombrado diario también se había comentado, en 1977, la presentación en la Alianza Francesa de Buenos Aires de ese primer volumen de una serie de seis anunciados, La voluntad de saber, con una muy expresiva bajada sobre la sexualidad y los mecanismos de su control social: "Así, el explosivo y complejo tema ha entrado definitivamente en los medios intelectuales argentinos". La crónica se refería al evento como a "una charla estructuralista sobre la sexualidad, en francés", una tarde de jueves y ante un auditorio de "maduras señoras". Se describía, en palabras del conferencista Frank Chapotot, el plan general del libro y se aducía que él "había logrado convertir una exposición soporífera en un momento divertido". No sólo es sugestivo, una vez más, el hecho de que el tema se tratara en un espacio público en esos años, sino sobre todo el que esta nota expresase ese intervalo en que podía situarse entonces a Foucault: entre lo que podría ser un espacio de circulación más académico y, en cambio, un ámbito en el que la temática parecía no importarle demasiado a un público principiante. La conclusión de la cronista habla por sí sola: "Si occidente padece, desde el siglo XVII, un ataque de verborragia sexual, ¿vale la pena protestar en seis tomos?" (Dujovne 1977: 19).

Antes aún, en la antesala de la dictadura y del desgajamiento de la confianza revolucionaria que sobrevenía en la militancia de izquierda, La Opinión había dado cuenta también del interés suscitado por "una de las cumbres del pensamiento estructuralista en Francia" con un comentario traducido de Le Nouvel Observateur sobre Vigilar y Castigar, recientemente publicado en Francia y editado en español en 1976. El título de la nota ("El Estado castiga el alma de los criminales con la misma crueldad que se aplicaba a los cuerpos en el siglo XVIII") parecía lacrar uno de los destinos de ese libro en el próximo y funesto presente (Enthoven, 1975: 15).

Pero incluso si esta circulación pública pudiese juzgarse menor, no deja de ser paradójico que, en 1980, Convicción -"el diario de Massera"7, aparecido en 1978 y dirigido por Hugo Ezequiel Lezamapublicara una volanta referida a Foucault que rezaba: "Para el genial francés, influyó más en la sociedad contemporánea el sistema de Bentham que Kant y Hegel". La nota no tiene desperdicio: enseguida se comentaba allí La verdad y las formas jurídicas (Foucault 1980) señalando, por ejemplo, que en el siglo XIX "la noción de prevención del delito hace que importe menos averiguar cierta verdad que establecer criterios de normalidad y anormalidad que permitan ejercer un control absoluto sobre los individuos", y citando a Foucault mismo: "Una serie de poderes laterales, al margen de la justicia, tales como la policía, las instituciones psicológicas, psiquiátricas, criminológicas, médicas y pedagógicas sirven para la corrección”. A continuación se atendía al panóptico, refiriendo nuevamente a Foucault en relación con el propósito a que sirve: "Es preciso que el tiempo de los hombres se ajuste al aparato de producción, que éste pueda utilizar el tiempo de vida de los hombres (...) Se busca la explotación de la totalidad del tiempo". Al fin se aludía a que esa "forma de totalitarismo es, sin duda, mucho más refinada en Occidente que en los países comunistas, donde se ejerce de manera más brutal: el ejemplo de las clínicas psiquiátricas para el tratamiento de la divergencia de opinión (que Foucault no cita) es, sin duda, el que más claramente ejemplifica este extremo del 
panoptismo". Y se concluía: "La verdad y sus formas jurídicas pone en cuestión la posibilidad de la mayor barbarie dentro de las civilizaciones más desarrolladas que conoció la historia. Según este criterio -y haciendo una reducción-, la diferencia entre Bokassa I y el sistema penal francés pasaría por un grado mayor de sofisticación" (Moreno 1980: 16). Foucault aparecía ahí como "genio", junto a referencias a Nietzsche, Deleuze y Guattari, a Platón y Sófocles.

En recuadro aparte, Gustavo Dessal comentaba El panóptico (1979), de Bentham, distribuido ese año en Argentina y que incluía la entrevista a Foucault titulada "El ojo del poder". Tras resaltar el engaño que implica que no se trate de una nueva traducción de la "célebre" obra de Bentham, sino que "en la Madre Patria se han limitado a fotocopiar la edición de 1834", Dessal destaca el "excelente" debate sobre Bentham que lo acompaña, a cargo de Foucault, Jean-Pierre Barou y Michelle Perrot. Finalmente se detiene en el panóptico: "Un principio que resumía en la metáfora de un ojo universal, presencia omnímoda y absoluta, la forma silenciosa y sofisticada que el poder adoptaría como resultado de las nuevas ideas de la Revolución Francesa. La violencia y la opresión físicas se reemplazarían, entonces, por este procedimiento que Bentham, hijo del Siglo de las Luces, inventó combinando los símbolos del ojo infinito, la luz y la transparencia" (Dessal 1980: 16).

Es elocuente que un diario que se rumoreaba era procesista, concibiera el panoptismo como tema de público interés o que ameritaba ser difundido. ¿Atender a que "la verdad misma tiene una historia", como decía Foucault, era en este caso una forma de criticar solapadamente al régimen? ¿O es que un discurso dispuesto para revelar y objetar el funcionamiento del poder disciplinario y la construcción a partir de las luchas del sujeto y el objeto en el conocimiento, terminaba aquí disimulando e integrando cínicamente un diagrama de poder dictatorial? Es difícil, si no imposible, determinar la intencionalidad del diario a este respecto, y no constituye nuestro objetivo. Lo que, en cambio, permite pensar es que quizás, en esas páginas destinadas a dar cuenta de las novedades culturales e intelectuales, las referencias a las elaboraciones de Foucault no estaban relacionadas con el ejercicio del poder estatal: a nivel social, no parecía haber una asociación directa entre la represión y las ideas foucaultianas.

Hay que decir que el diario negó haber sido fundado por el almirante Emilio Eduardo Massera y que en sí misma no dejaba de parecer ambigua y contradictoria la secuencia de sus publicaciones ${ }^{8}$ : Desde su sección internacional, Convicción miraba al Este con algo de obstinación, en sucesivas noticias relativas a la Unión Soviética, China y Cuba; en política nacional, se dedicaba mayormente a la cuestión gremial, la condena a la subversión, los planes económicos y las actividades vinculadas a la Junta Militar (especialmente cuando se tratara de actos y/o elocuciones de Massera); las páginas culturales, por su parte, transitaban por intelectuales como Bertolt Brecht, Susan Sontag, Gaston Bachelard, el humor popular soviético, el psicoanálisis o la muerte de Oscar Masotta en Barcelona. Ciertamente, machacaban sobre la "agonía" de la doctrina marxista, por ejemplo en la reiterada voz de los nuevos filósofos franceses que "entierran" a Marx (Delgado 1980). Pero, al mismo tiempo, publicaban notas sobre el "extremismo de derecha" en Alemania, o incluso referían a actividades en el Pompidou que promovían la lectura "sin censura". En ese marco, menciones breves a Foucault habían aparecido y aparecerían en diversas ocasiones: los 35 años de la editorial Paidós, la relación entre Foucault, Derrida y Lacan, la muerte de Barthes, etcétera. El pensador francés, por tanto, no era una referencia censurada y su cita, aun aquella que denunciaba en cada gesto la opresión y que menos convendría al régimen, aparecía en la prensa escrita.

Ahora bien, más allá de la presencia pública en diarios y revistas, algunos escritos de Foucault también se difundieron durante la dictadura en grupos de estudio extraacadémicos de estudiantes de filosofía, en bares y en forma de fotocopias clandestinas, en tanto prácticas de lectura concretas y colectivas. En los primeros años 80, El orden del discurso (Foucault 1973) circuló junto a lecturas de Marx, de estructuralistas franceses, de Lucien Sève y Lucien Goldmann. Esas copias ponían entonces sobre la mesa la cuestión de la política de la verdad, y también la dificultad hasta lo imposible de desprenderse de la sombra de Hegel. Si aquellos estudiantes habían encontrado en Hegel un punto de partida para pensar políticamente la relación con el Estado, el significado de la militancia y de las luchas latinoamericanas de los '60, Foucault los impactaba ahora y acompañaba una ruptura con aquella visión del mundo ${ }^{9}$. Resulta que, de manera evidente, la crítica que emprendía Foucault del marxismo vulgar y la concepción estadocéntrica de la política comenzaba lenta pero fuertemente a ser un motivo para repensar la radicalidad militarista de la experiencia política de masas de los años 60 y 70. 
Por otro lado, una dimanación interesante se vincula expresamente con el ámbito académico, en este caso con la Universidad de Buenos Aires (UBA). Allí, ya en 1977, por ejemplo en los cursos de Psicología Institucional de la carrera de Psicología, se trabajaba Historia de la locura en relación con la psicología en las instituciones psiquiátricas, las concepciones históricamente determinadas de la locura y el enfoque estructuralista $^{10}$. Aquella lectura alumbrada por la problemática del poder en las instituciones y el desarrollo del psicoanálisis institucional teje relaciones hacia atrás y hacia delante: por un lado, con lecturas realizadas desde espacios como el grupo Plataforma a principios de los '70; por otro, la continuidad se percibe también en el caso de la Revista Argentina de Psicología en 1980. Vale mencionar que esta presencia habilitaba una difusión cada vez mayor, desde los reductos intelectuales hacia el público masivo.

En definitiva, mientras el nombre de Foucault y la referencia a algunos de sus textos e ideas transitaban por espacios subterráneos y aparentemente sus libros difícilmente se conseguían en librerías, hay que decir que también circulaban en periódicos de venta pública y en instituciones como la Alianza Francesa y la UBA. De lo anterior se desprende, entonces, la inexactitud de la inferencia señalada al inicio acerca de la censura que habría podido caer sobre el pensador del poder, las disciplinas y el control social en tiempos de la dictadura. Posiblemente esto remita a un efecto habitual en aquellos años producto de la dificultad de discernir entre lo efectivo de la prohibición, por ejemplo de este autor, y el lugar de esas interdicciones en la vigilancia autoimpuesta por editores y lectores. Dicho de otro modo: se desprende que el dispositivo de pensamiento que podemos llamar "Foucault", pese a la asfixia generalizada que provocaba la censura, tuvo la suficiente capacidad como para manifestarse de manera fluida y serpenteante en múltiples circuitos, espacios y prácticas.

\section{Violencia política, poder y sujeto: el grado cero de la resistencia}

Aquella circulación de los escritos del pensador francés en tiempos opresivos pronto comenzaría a brindar una clave de lectura de lo que sucedía en el país. Ciertamente, también Vigilar y Castigar (Foucault 1976) circuló en los tempranos ' 80 en las facultades, por fuera de los programas oficiales. La aparición de un análisis centrado en el poder, como el que venía a ofrecer ese libro, marcaría una apropiación local de las ideas de Foucault determinada por el terrorismo de Estado, amarrada a los dispositivos de represión y control social. Ese texto "era una especie de santo y seña de la resistencia, leído con fervor dado el contexto afirmaba hace pocos años la historiadora Lila Caimari-. (...) Las imágenes opresivas del panóptico y las técnicas de control fueron leídas como metáforas de la violencia lisa y llana de la tortura alojada en el cuerpo que el Estado argentino desplegaba por entonces (...) La adhesión que generó ese Foucault excedía ampliamente la adhesión teórica porque sus descripciones hipnóticas de las tecnologías y dispositivos de represión normalizada, de esas sobrecogedoras miradas del poder sobre estos sujetos minúsculos que son los depositarios de control, se difunden en esos años oscuros de la Argentina, en los que no había que ir muy lejos para encontrar un referente muy concreto a esas imágenes" (Caimari 2005: 15-16). Una lectura que, indudablemente, no podía menos que producir estremecimiento y empatía ante la problemática compartida de la dominación social. Una lectura, sin embargo, no exenta de tensiones.

Es nítida la imagen del efecto persuasivo y cautivante de Vigilar y Castigar, tanto desde los postulados teóricos como desde la narrativa, para mirar ahí las ejemplificaciones del terror. Pero, ¿había mirado la sociedad argentina de entonces el castigo? ¿Se podía asociar el relato foucaultiano a la información que, por ejemplo en el contexto de la transición a la democracia, empezaba a aparecer en los diarios sobre la tortura y la desaparición? Si la crónica que inicia el libro, la del suplicio de Damiens, el gran ritual público del castigo en pleno día, podía aplicarse a la situación argentina, esto sólo era así parcialmente, puesto que el castigo constituido por el dolor físico inscripto al cuerpo del supliciado se interrelaciona con el ceremonial público para el ejercicio del poder, que no tenía aquí semejante (en el castigo-suplicio la muerte no es clandestina); y si las minuciosas descripciones de la modalidad panóptica del poder, la receta penitenciaria oculta, gradual, de la docilidad inoculada en pequeñas dosis, no tenían prácticamente correlación posible con el caso argentino, transmitían sí esa representación de una vigilancia constante, de la producción de disciplina, del cuerpo como materialidad y blanco del poder. Pareciera que, aun cuando pudiesen ser fácilmente asidas como ideas compartidas, ni una ni otras se "adaptaban" precisamente a los horrores de la dictadura, a los 
suplicios impartidos en los centros clandestinos de detención. Como sintetizaba Caimari, "en los '70, Foucault nos llegó en francés y traducido al español" (Ibid: 16) ${ }^{11}$.

Se trataba entonces de lecturas literales, fascinadas también ante la audacia y la habilidad estilística. Al filo de ese momento de transición a la democracia que fue en Argentina de una enorme potencia, las lecturas de Vigilar y Castigar se hacían, pues, desde un entusiasmo acrítico -la especificidad del contexto de producción de Foucault no era un elemento tomado en consideración-. Algo de lo olímpico de su prosa invitaba a leerlo fuera del tiempo y el espacio. Pero habría que aducir y resaltar, por otra parte, lo público de la muerte en esos años, de cadáveres mutilados en las calles y en las plazas (Calveiro 1998: 149), y reparar en la fuerte impregnación de ese texto como absolutamente solidaria al contexto argentino: apenas leer las páginas de la tortura aplicada a Damiens podía llegar a ser un modo de presentificar, acaso de acompañar, la tortura real.

Así, mientras a un nivel más amplio y generalizado de la sociedad argentina parecían no encontrarse asociaciones directas entre la represión y las ideas foucaultianas -aparente ausencia de tensiones que permitía que su nombre circulara incluso en diarios vinculados a miembros de la Junta Militar-, en otros sectores, más reducidos, tenían espacio lecturas que hallaban nexos evidentes entre ese libro y el contexto local. Es que en aquel momento político de disponibilidad sorpresiva y simultánea de información sobre los años inmediatamente anteriores, Vigilar y Castigar podía expresar también ese clima de denuncia compartido, de desenmascaramiento y el espíritu de ir a contrapelo de la idea consagrada de la prisión como forma de castigo liberal y de avanzada ${ }^{12}$. En definitiva, para quien tuviese los ojos abiertos, Foucault era una usina central para comprender y actuar en la desquiciante realidad local, más aún considerando que provenía de la arraigada y familiar tradición crítica cultural francesa.

Es en el campo jurídico donde el efecto de las elaboraciones foucaultianas puede verse claramente. Si acaso Foucault supo definir a la ley como una simple gestión de los ilegalismos, esa fórmula que en Francia podía resultar ingeniosa aquí se parecía dramáticamente a la violencia descontrolada del Estado. A fines de los años 70, un marxista althusseriano como Enrique Eduardo Marí ofrecía en la Alianza Francesa alguna charla sobre Vigilar y Castigar. Sobre ese hecho, recordaba Tomás Abraham: "Una gacetilla en un diario [en 1979] hablaba de una conferencia de Foucault en la Alianza Francesa. No me parecía cierto que Foucault llegara al país durante la dictadura y por mis pocos contactos en Francia nada hacía previsible su visita. Llamé por teléfono y me dijeron que un abogado y filósofo, el doctor Marí, daría aquella tarde una conferencia sobre la obra de Michel Foucault y que el anuncio había deslizado un pequeño error. Cuando llegué, me encuentro con una sala con unas siete u ocho señoras enfundadas en pieles y alguno que otro señor" (Abraham 2001). A continuación, aludía así a uno de los oyentes presentes en aquella ocasión: “(...) Enrique me comentó que lo había enviado la SIDE para averiguar algo sobre él y su discurso. Como no entendió nada, Enrique me decía, risueño, que el hombre lo había llamado por teléfono para pedirle algunas pistas sobre la conferencia porque no lograba elaborar su informe (...) En aquella época [yo] daba clases sobre Foucault en la Asociación de Psicólogos de Buenos Aires y le sugerí la posibilidad de tender puentes entre nuestras islas. Eran tiempos de terrorismo de Estado, en que transmitir pensamientos del estilo de los de Foucault era riesgoso. Nos alegró saber de nuestra mutua existencia" (Ibid). Aun con las inexactitudes y los inevitables remiendos que el ejercicio de la memoria opera sobre los recuerdos, no deja de ser significativo el testimonio al dar cuenta de la presencia pública de Foucault y de un sistema de control cultural en esos años que, en ocasiones, podía llegar a ser tan capilar como ineficaz.

En relación también con Vigilar y Castigar, Marí participaría poco después, en 1982, en la obra colectiva El discurso jurídico y en el Primer Congreso Internacional de Filosofía del Derecho de La Plata, proponiendo reponer la lectura teórica de Jeremy Bentham en los textos de Foucault y de Lacan. Algunos de esos aportes, que alertan sobre la necesidad de atender al carácter específico del pensamiento de Foucault, están reunidos en La problemática del castigo, gestado en estrecho vínculo con los debates políticos de la transición a la democracia. Desde la filosofía del derecho penal, Marí presenta ahí una obra erudita y precursora en la aplicación de tesis foucaultianas al campo jurídico local: recuperando la originalidad de Bentham, ante la idea extendida del "panóptico de Foucault", el libro está dedicado al discurso del radical inglés y a su lectura por Foucault. Acuciado por el ejercicio del castigo "como una reminiscencia de la barbarie escondido en la ideología de la seguridad nacional y otros eufemismos", este abogado y filósofo señala la diferencia que implica que en el castigo-suplicio se inscriba el dolor "al cuerpo del supliciado en un 
ceremonial público en el que la justicia se manifiesta en su fuerza (...) Nada de dolores hurtados al oído público ni de cuerpos desaparecidos a la mirada" (Marí 1983: 164-165).

Hay al menos dos elementos que ameritan ser subrayados en este trabajo. Por un lado, la extensión que Marí practica de los enunciados de Foucault respecto del discurso del poder (sobre todo desde La voluntad de saber, pero no sólo) hacia el discurso jurídico. La regla de la polivalencia táctica de los discursos y la idea de que cada sociedad tiene su régimen de verdad traman sus propios enunciados en función de demostrar que lo esencial del problema del castigo se vincula a que "los argumentos morales que lo justifican, y su autoreclamada racionalidad, no tienen un campo de asignación inmóvil sino dependiente de la posición estratégica en que las respectivas tesis [retribucionista o utilitarista] se sitúen" ${ }^{13}$. En ese sentido, a través del ejemplo de Luis XVI y los discursos pronunciados en la Asamblea General a favor de la pena de muerte, analiza cómo esa sociedad había cambiado su "política general" de la verdad. Como ya lo ha señalado la socióloga e historiadora Dora Barrancos: "Marí agregó otros discursos a la analítica de Foucault en orden a observar cómo se alteraban (y alternaban) motivos utilitarios y redistributivos en la posición estratégica, entre ellos los discursos de Fouché y Saint-Just (...) Es más, Marí pudo observar que Fouché se había pasado a una y otra posición (justicia y didactismo, ambos beneficios serían ofrecidos por la condena a muerte del Rey) ofreciendo la prueba de la posición estratégica del nuevo discurso de la verdad" (Barrancos 2005). Así, Marí apuesta finalmente a que, más que una analítica de las tesis retribucionista y utilitaria, habría que apelar a una "economía política" de la verdad de ellas, "a sus instancias y mecanismos de aplicación, a sus condiciones de aparición y funcionamiento” (Marí 1983: 95).

En relación con lo anterior, un segundo elemento a destacar parte de su formulación de la siguiente pregunta: "Y si al entrar con Bentham los cuerpos en el panóptico, entran con ellos las fuerzas del castigo y las fuerzas de la economía en su noción más lata, la aplicación del diagrama de arquitectura al discurso utilitarista penal de Bentham, por parte de Foucault, ¿lo iba a dejar intangible, o por el contrario, lo retraduciría sacándolo del marco habitual de una teoría de justificación jurídica o moral del castigo?" (Ibid: 202). A partir de ella, expone la claridad con que encuentra en Foucault (el de Vigilar y Castigar) la comprensión de la irrupción de una nueva tecnología del poder, una tecnología del cuerpo, una historia política de los cuerpos y su disciplinamiento, menos una economía política que una anatomía política, el castigo al costado del discurso jurídico y moral ${ }^{14}$. Y es más, termina por plantear el fracaso del modelo panóptico, de esa gran utopía del iluminismo de la transparencia en las prisiones y en la sociedad ${ }^{15}$ : "Después del panóptico no prevaleció en las cárceles la disciplina-producción de Bentham, ni la disciplina de Foucault, sólo permaneció la vieja, la única disciplina. La prisión permaneció en sombras. El castigo sumió a la sociedad en sus formas sociales y políticas más aberrantes y sombrías” (Ibid). Aquí, como en los otros escritos de Marí, su apropiación de Foucault está trazada por la presencia de los cuerpos humillados y el sufrimiento de los antepasados.

Para entonces, Marí ya había publicado su texto sobre el crimen de Pierre Rivière, caso que había ganado en París nueva actualidad a partir de su relectura y debate. Ahí, Pierre Rivière constituye, para Marí, un modo de anticipar la historia de las prácticas penales en relación con la anatomía política más que como efecto de las teorías jurídicas, y establece ya una deriva estimulante: "Estos análisis [los de Foucault en Vigilar y Castigar o bien en La voluntad de saber] de desciframiento del doble juego poder-saber pueden arrojar valiosas sugerencias sobre la forma de composición del discurso jurídico, en el sentido de la tesis que he propuesto sobre la existencia de una distancia y una ruptura entre el proceso de producción y el producto jurídico. Para ello tendremos que violentar el marco que el propio Foucault fijó en su investigación" (Marí 1993: 256-257).

Practica, así, una extensión del análisis de Foucault más allá de su región de origen, partiendo por ejemplo del caso Rivière como conjunto de sugerencias sobre la forma de composición del discurso jurídico y como contribución crítica para la teoría jurídica. Es muy interesante cómo, una vez más, con rigor y erudición, pone en relación a Rivière -especialmente un aspecto de su biografía: su sadismo hacia animales y niños- con un caso de la criminología argentina, olvidado en los archivos: el de Cayetano Santos Godino. ¿Qué tiene para decir el "Petiso Orejudo"16? ¿Cómo se construye y metamorfosea el discurso jurídico a través de batallas? 
La tesis que traza el trabajo es la ausencia de uniformidad y de homogeneidad semántica en el discurso jurídico, discurso que se constituye en un proceso discontinuo donde intervienen y se entrecruzan con él otros discursos. Así, "entre el proceso de formación y el producto-final formado hay una ruptura, una distancia, una brecha" (Ibid: 289). Lo que lleva a concluir que "la verdad del resultado no es una verdad metafísica, no hay verdad ni por descubrimiento de la esencia del sistema ni por desencubrimiento. Tampoco es una verdad verificacionista. (...) Es una verdad producto de una lucha en el seno de una relación conocimiento-poder (...) una verdad redondamente racional. Representa la racionalidad de una sociedad en un momento dado de su desarrollo, el conjunto de valores e ideología de una estructura político-social que no siempre coincide, y sobre todo en los casos límite, con el sistema jurídico que la expresa" (Ibid: 282). Al fin, pues: "El discurso jurídico debe comprenderse y evaluarse no sólo por lo que descarta de sí sino por lo que atestigua con esa exclusión (...). El discurso jurídico es en gran medida un discurso clandestino" (Ibid: 290) ${ }^{17}$.

Pero esta sintomática presencia en el discurso jurídico partía incluso de la cárcel misma. En 1978, Emilio de Ípola preparaba desde el exilio mexicano una primera versión de La bemba. El texto, elaborado a partir de la experiencia de su secuestro y detención por un comando del Primer Cuerpo del Ejército durante la dictadura militar, se proponía describir el modo de funcionamiento del rumor en la cárcel política. Escrito mayormente olvidado, La bemba no pretendía formar parte de la literatura de denuncia referida a esa época sino que se presentaba como un intento de análisis del fenómeno discursivo constituido por esa expresión cubana que designa al rumor, esos "fragmentos de un discurso desarmado y precario. Frases transmitidas de celda a celda, de pabellón a pabellón, e incluso de prisión a prisión (...) Pero, sobre todo, exorcismos contra la ignorancia, la desinformación, la incertidumbre" (De Ípola 2005: 16). Años después discernía que se contenía ahí una "única preocupación teórico-metodológica; a saber, la de pensar el estatus específico (otros dirían ontológico) de lo discursivo en el universo de lo social-histórico" (Ibid: 12). El hecho de que él fuera parte de aquello que se disponía a analizar le valió cuestionamientos sobre la falta de "rigor científico", por ejemplo, o acerca de incurrir, a partir de su propio punto de vista, en generalizaciones: "Me tomé a mí mismo como encarnación de la figura del Panóptico (un Panóptico idealizado, capaz de ver inclusive lo que no era visible), es decir, como encarnación de aquella misma figura que yo había descartado $-\mathrm{y}$, para ser sincero, sigo descartando- para dar cuenta de la principal modalidad de ejercicio de la vigilancia carcelario-política" (Ibid: $9)^{18}$.

Dedicado a los presos políticos de la dictadura militar - detenidos en su mayoría en el marco del estado de sitio que rigió desde octubre de 1974-, el filósofo y Doctor en Ciencias Sociales describía ahí características de la producción, circulación y recepción de las bembas en el tiempo y el espacio carcelarios. Para ello, remitía a Foucault y a Goffman ${ }^{19}$, en relación especialmente con el funcionamiento del sistema carcelario a que se encontraban sometidos los presos políticos en Argentina, la violencia física y la más sutil producida por la desinformación sistemática de los detenidos y garantizada por un conjunto de prácticas (de las requisas, pasando por la prohibición de hablar con los guardias o de reunirse en grupos numerosos, al traslado o la rotación del personal de vigilancia). Se aludía, también, al ejercicio sistemático de "una vigilancia constante, silenciosa y alerta (y a menudo invisible para los presos)" y a que esa "disimetría reglamentada entre un desconocimiento y un saber que se quieren, ambos, integrales (y sobre lo cual Foucault ha dicho lo esencial) parece asumir, en las cárceles para detenidos políticos, características especiales" (Ibid: $25)^{20}$. Finalmente, describía las técnicas para contrarrestar esa vigilancia que se quiere invisible, las brechas que permiten vigilar a quienes vigilan y crear circuitos de comunicación clandestinos: las bembas podrían, en un sentido, constituir "el grado cero de la resistencia interna de los presos políticos a la desinformación erigida en sistema; la forma primera y más elemental de oponerse materialmente (y colectivamente) a la violencia de la incomunicación regimentada" (Ibid: 59).

Ciertamente, aquí podemos encontrar una suerte de clave del período. Por un lado, en la Argentina de aquellos años pensar en la disciplina carcelaria tenía poco de la reflexión que podía elaborarse plácidamente desde el Quartier Latin y mucho de la opresiva puesta del cuerpo en la cárcel misma de manera violenta. Por otro, así como el espacio público se encontraba bajo un estricto sistema de control, la resistencia adquiría los contornos del rumor carcelario aun a la luz del día; obligada a la clandestinidad, la libertad seguía su curso ${ }^{21}$.

\section{Conclusiones}


Una cada vez más amplia recepción de Foucault se evidencia a partir de comienzos de la década de 1980, cuando la circulación de alusiones al pensador francés se torna sistemática. En los años de la postdictadura se afianzará notablemente en un vasto sector del campo intelectual el interés por sus textos. Las palabras clave y la cita foucaultianas pasarán a formar parte ya de una suerte de moda intelectual; en el peor de los casos, de un lugar común profusamente disciplinado ${ }^{22}$; en el mejor, de una referencia ineludible para entender la entera época por la que aún se transitaba.

Antes de eso, hemos procurado aquí seleccionar algunos casos con el propósito de reconstruir un momento de la recepción argentina de las obras de Michel Foucault. En esa búsqueda encontramos un conjunto de circulaciones, mediaciones y usos que permiten afirmar que el nombre y la cita foucaultianos tuvieron su espacio en tiempos de la última dictadura militar argentina. Como tuvimos ocasión de exponer, se trató de apropiaciones que no fueron unívocas y que estuvieron siempre permeadas por la coyuntura local, de modos de lectura y usos que se han perpetuado hasta el presente y que van de los más reproductivos a los profundamente críticos. Foucault los permite todos. Como deriva reproductiva, se encuentran operatorias del poder y panópticos en dondequiera; en su arista crítica, se entiende la necesidad de matizar la capacidad real de las instituciones de control social y se intenta atender a las especificidades del contexto argentino. En uno y otro caso, asistimos a la representación del pensador francés como historiador del castigo y el encierro, como pensador de una nueva radicalidad política crítica de la dominación, en el que se condensa la imposición de la dictadura militar y la crisis de las esperanzas revolucionarias, pero casi siempre abonando las estrategias de construcción de la sociedad civil.

Por otra parte, frente a la imagen de la dictadura como "edad oscura", vale subrayar las resistencias que continuaron pensando en condiciones ciertamente hostiles; un pensamiento no carente de nuevas elaboraciones. Puesto que, si a partir de los primeros '80, las lecturas de Foucault salen con fuerza a la luz es, también, porque ya venían siendo elaboradas en el contexto de la dictadura. Así, intentamos atender a qué sucede con el espacio público en condiciones de opresión total, de cara a lo real del encierro, cuando el mismo está negado. Ante las dificultades que acarrea verlo nítidamente en el contexto de la dictadura, lo hemos rastreado en los libros, los programas universitarios, las menciones entrelíneas. Y lo encontramos incluso en instituciones, diarios y encuentros colectivos. Su presencia fue tan "visible" como "clandestina". En este sentido, podría decirse que el espacio público aún se palpaba, y si en buena parte los usos de Foucault tenían la forma de "estructuras sumergidas de la acción" (Melucci 1994), al borrarse las condiciones generales de opresión emergerán con toda su fuerza. Prueba de ello es que Foucault así como el entero postestructuralismo han sido claves en la narrativa emancipatoria del campo político-cultural latinoamericano de la postdictadura.

\section{Notas}

${ }^{1}$ El tiraje promedio estuvo entre 3,8 y 4,7 (miles) entre 1976 y 1980 , mientras que entre 1971 y 1975 oscilaba entre 6,3 y 10,1 (miles). Es
posible visualizar la disparidad de la producción de libros entre Capital Federal y las provincias teniendo en cuenta que, mientras entre
1980 y 1983 en la primera se producían alrededor de 4 mil libros, en las provincias la cifra rondaba los 400 . Otro dato interesante para ese
período es que el 16,5\% fueron títulos traducidos de otros idiomas; de ellos, el 17,7\% correspondió al idioma francés (798 títulos en el
período 1980-1984) (Getino 1995: 56-60).

${ }^{2}$ La oficina local de la editorial Siglo XXI, en Perú 952, fue allanada el 2 de abril de 1976 por un grupo de tareas de la Marina.

${ }^{3}$ La revista fue inicialmente pergeñada en Buenos Aires por Carlos Altamirano, Ricardo Piglia y Beatriz Sarlo en coincidencia con dirigentes de la izquierda revolucionaria. Vale subrayar que, en esos años oscuros, se trataran en sus números temas relacionados con las ideologías contemporáneas en donde, sin dudar, hacían circular también a Marx y el marxismo.

${ }^{4}$ Los artículos que Vezzetti produce en estos años se vinculan con La locura en la Argentina, libro que publicará en 1983 por la editorial Folios. Entre otros, "Ideología y psiquiatría: nacionalidad, raza, disciplina social" (Punto de Vista 1982), o los textos que elabora también durante este período para la Revista Argentina de Psicología. Además, el comentario de El amor del censor, de Pierre Legendre, donde a través de la relación entre poder y deseo remite en este caso a Vigilar y Castigar y postula que la "afinidad con textos de Deleuze y Foucault salta a la vista" (Punto de Vista 1981: 32-35). Además, es interesante señalar que Vezzetti participa de La Escuelita, escuela de enseñanza privada de arquitectura gestada desde la sociedad civil y que funcionó durante los años de la dictadura militar ofreciendo los cursos que, entre otros, dictaban Beatriz Sarlo y Francisco Liernur. En ese contexto, Vezzetti dicta en 1982, por ejemplo, el curso titulado "Michel Foucault: Para una analítica del saber y el poder".

${ }^{5}$ En 1981, hacia el final de este período, por ejemplo, la distribuidora Catálogos publicita la edición española de Esto no es una pipa. Ensayo sobre Magritte. 
${ }^{6}$ Sitio fue una publicación periódica porteña que circuló entre diciembre de 1981 y noviembre de 1987, y cuya redacción estuvo compuesta por Ramón Alcalde, Eduardo Grüner, Jorge Jinkis, Luis Gusmán, Mario Levín, Luis Thonis. En el segundo número se sumaron Héctor Grifasi y Hugo Savino. Entre sus colaboradores se encontraba Néstor Perlongher.

${ }^{7}$ Emilio Eduardo Massera fue Comandante de la Armada Argentina y uno de los hombres del régimen militar con mayor poder.

${ }^{8}$ Se enunciaba ahí que el periódico había sido fundado por Hugo Ezequiel Lezama, junto con un "grupo de periodistas profesionales, Héctor Grossi, Mariano Montemayor y Julio Ardiles Gray". Y se afirmaba: "Sólo nos propusimos ejercer la docencia cívica y ser observadores críticos del gobierno, pero desde adentro del Proceso de Reorganización Nacional y no fuera de él" (Convicción 1980).

${ }^{9}$ Comunicación personal con Susana Murillo, 23/12/2008.

${ }^{10}$ Foucault comparte ahí la bibliografía con Freud, Goffman, Piaget, Bleger, Ulloa y otros. El profesor titular de Psicología Institucional en ese momento era Luis M. Bick.

${ }^{11}$ En este sentido, podía ser todo un símbolo, si se quiere, la misma edición de tapa negra, frente a la blanca y limpia de la prestigiosa casa Gallimard.

${ }^{12}$ Comunicación personal con Lila Caimari, 28/05/2009. En relación con lo anterior, señalemos precisamente, entre los movimientos de la universidad tras la dictadura, la creación de la "Universidad en la cárcel".

${ }^{13}$ A la hora de especificar, tal como las define Marí, la tesis utilitarista apela a las consecuencias valiosas del castigo (disuasión, prevención, reforma), en tanto que la retribucionista justifica el castigo en razones de justicia (retribución o reparación de una acción). De ese modo, retribucionismo y utilitarismo, "según los fines políticos o de organización social que se persigan, pueden operar ya sea aislados y contradictorios o bien combinados y comprometidos en la misma acción (...) Para comprender a fondo el valor de las tesis retribucionista y utilitarista, hay que verlas en sus condiciones de aparición y realización, y no como meros discursos consumados". Enseguida introduce el discurso del poder foucaultiano para aplicarlo a estas tesis centrales, sugiriendo hacer de ellas esta lectura: "No hay que imaginar un discurso utilitarista aceptado y otro retribucionista excluido -o a la recíproca- que estuviesen insertos siempre en la misma estrategia. Hay que restituirlos con lo que acarrean de cosas dichas y ocultas, de enunciaciones requeridas, complementarias o prohibidas, con las variantes y los cambios que suponen quién habla, su inscripción en el poder y el contexto institucional en el que se halle colocado el portador del discurso" (Marí 1983: 85-86).

${ }^{14}$ Para Marí, si el retribucionismo se preguntaba por qué se castiga (con vistas al pasado) y el utilitarismo para qué se castiga (con vistas al futuro), Foucault se pregunta cómo se castiga (con vistas a las condiciones históricas de constitución de esos discursos, sin echar mano para responder de discursos jurídicos o morales) (Ibid: 172).

15 “Las utopías -dice Marí-: tanto más justas cuanto más imposibles, tanto más imposibles cuanto más justas” (Ibid: 202).

${ }^{16}$ Cayetano Santos Godino, más conocido como el "Petiso Orejudo", fue responsable del asesinato de una serie de niños a comienzos del siglo XX.

${ }^{17}$ Otro ejemplo de su traslación de postulados foucaultianos al análisis local está presente en su "José Ingenieros: el alienista, su loco y el delito", publicado inicialmente poco después, en 1981. A partir de Historia de la locura, Marí piensa allí las características y la temporalidad de dos universos de relación entre locura y experiencia: uno, el de la locura inscripta en un universo de experiencia cósmica, dice Marí, que sería en Foucault la locura trágica del mundo; otro, el de la locura en el universo de la responsabilidad individual, la locura que "pasa de la Naturaleza a la Sociedad" (Marí 1993: 185). A partir de los cambios del estatuto social y antropológico de la locura, analiza la irrupción de la figura del alienista y el rol de José Ingenieros en la psiquiatría y criminología argentinas.

${ }^{18}$ De Ípola refiere a algunas de estas cuestiones en la introducción y, ante los supuestos discutibles del texto, recuerda el "carácter modestamente descriptivo" del mismo. La bemba fue publicado inicialmente en Ideología y discurso populista (1982).

${ }^{19}$ La referencia a Foucault le servía para enfatizar que la violencia contra el cuerpo no está ausente incluso en los regímenes carcelarios más avanzados. En cuanto a Erving Goffman, aludía al concepto de "instituciones totales" y subrayaba la "mortificación del yo a través del cuerpo". Quedaba así manifiesto el efecto de Vigilar y Castigar y de Internados. Ensayos sobre la situación social de los enfermos mentales que "han sido de suma utilidad para este trabajo" (De Ípola 2005: 19).

20 "La cárcel política lleva a sus últimos extremos los mecanismos que aseguran una distancia máxima entre el saber de las autoridades y la ignorancia de los detenidos" (Ibid: 26). De Ípola recalcaba aquí la diferencia, sustentándose en la cita a Foucault, entre la prisión política y la cárcel para presos de derecho común: mientras en la última sería posible "detectar una funcionalidad positiva", en la primera se haría evidente la "incapacidad de la autoridad político-militar de funcionalizar positivamente la ilegalidad política. A consecuencia de lo cual, la cárcel política se agota casi enteramente en sus funciones negativas" (Ibid: 28-29). No todo preso era considerado por el autor como político.

${ }^{21}$ Finalmente, quisiéramos apenas apuntar algunas referencias, entre otras, que se relacionan con las problemáticas de este período. Por ejemplo, también desde México el sociólogo argentino Ernesto López, entonces investigador de FLACSO, trabajaba sobre Vigilar y Castigar en el artículo titulado "El poder disciplinario de Foucault" (1979). Ahí establecía la centralidad y la importancia de la investigación del poder disciplinario al tiempo que señalaba el hecho de que las disciplinas han sido ignoradas por la mayoría de los historiadores y científicos sociales. Oscar Terán, por su parte, editor de la revista Controversia y uno de los precursores en la introducción de Foucault en la historia de las ideas latinoamericana, elaboraba una serie de escritos estrechamente relacionados con los postulados del pensador francés, que iban desde la presentación de sus ideas hasta análisis en los que las mismas operaban con fuerza. 
Por ejemplo, escribía en México la primera versión sobre la obra de José Ingenieros (1979) donde interviene su lectura de Vigilar y Castigar. También desde México, presentaba y compilaba El discurso del poder (1983). Por último, aun cuando no se hiciese explícito, ese clima de época vinculado con las elaboraciones de Foucault podría también pensarse presente en textos como "La rebelión del coro", de José Nun (1984).

${ }^{22}$ En palabras de Dora Barrancos: "El abuso de las nociones foucaultianas amenaza con transformarlas de instituyentes en instituidas, deriva que hubiera estremecido a su autor. Pero insistiendo en el abuso, a menudo la apelación a sus categorías da la impresión de maniobras reificantes que exhiben una fetichización del autor" (2005). En el mismo sentido corrían las frecuentes alusiones que Terán hacía en los últimos años a la "máquina Foucault".

\section{Bibliografía}

Abraham, Tomás (2001), "El detective filosófico: Enrique Marí (1928-2001)”, en Radar, 8 de julio de 2001, Buenos Aires.

Barrancos, Dora (2005), Usos (y abusos) de Foucault en la Argentina, conferencia en el Seminario Internacional de Homenaje a Michel Foucault, Santiago de Chile.

Bentham, Jeremy (1979), El panóptico, La piqueta, Madrid.

Caimari, Lila (2005), "Usos de Foucault en la investigación histórica", en Documento de Trabajo $\mathrm{N}^{\circ} 18$, UdeSA, Buenos Aires.

Calveiro, Pilar (1998), Poder y desaparición: los campos de concentración en Argentina, Colihue, Buenos Aires.

Convicción (1980), "El diario La prensa también puede equivocarse”, en Convicción, 7 de junio de 1980, tapa, Buenos Aires.

De Ípola, Emilio (1982), Ideología y discurso populista, Folios, México.

Ídem (2005), La bemba: acerca del rumor carcelario y otros ensayos, Siglo XXI, Buenos Aires.

Delgado, Osvaldo (1980), "Nuevos pensadores y economistas entierran en Francia a Marx y a Keynes", en Convicción, 31 de enero de 1980, contratapa, Buenos Aires.

Dessal, Gustavo (1980), "Panoptismo y sociedad”, en Convicción, 11 de noviembre de 1980, p. 16, Buenos Aires.

Dujovne Ortiz, Alicia (1977), "Foucault, la sexualidad humana y la verborragia", en La Opinión, 7 de setiembre de 1977, p. 19, Buenos Aires.

Enthoven, Jean-Paul (1975), "El Estado castiga el alma de los criminales con la misma crueldad que se aplicaba a los cuerpos en el siglo XVIII", en La Opinión, 12 de setiembre de 1975, p. 15, Buenos Aires.

Foucault, Michel (1967), Historia de la locura en la época clásica, FCE, México.

Ídem (1973), El orden del discurso, Tusquets, Barcelona.

Ídem (1976), Vigilar y Castigar. Nacimiento de la prisión. Siglo XXI, México.

Ídem (1977), Historia de la sexualidad (vol. 1: La voluntad de saber), Siglo XXI, México.

Ídem (1980), La verdad y las formas jurídicas, Gedisa, México.

Getino, Octavio (1995), Las industrias culturales en la Argentina, Colihue, Buenos Aires.

Grüner, Eduardo (1981), "El festín de la letra. A la manera de Rabelais", en Sitio N 1, pp. 13-20, Buenos Aires.

Gusmán, Luis (1983), “Del destierro al exilio: versiones e inversiones”, en Sitio Nº 3, Buenos Aires.

H.V. (seud. Hugo Vezzetti) (1982), "Oscar Landi, Crisis y lenguajes políticos”, en Punto de Vista $\mathrm{N}^{\circ}$ 16, p. 34, Buenos Aires. 
Invernizzi, Hernán y Gociol, Judith (2002), Un golpe a los libros. Represión a la cultura durante la última dictadura militar, Eudeba, Buenos Aires.

Legendre, Pierre, et al. (1982), El discurso jurídico: perspectiva psicoanalítica y otros abordajes epistemológicos, Hachette, Buenos Aires.

López, Ernesto (1979), "El poder disciplinario de Foucault", en Revista mexicana de sociología $\mathrm{N}^{\circ}$ 4, pp. 14211432, México.

Marí, Enrique (1983), La problemática del castigo. El discurso de Jeremy Bentham y Michel Foucault, Hachette, Buenos Aires.

Ídem (1993), Papeles de filosofía (...para arrojar al alba), Biblos, Buenos Aires. Contiene: “Moi, Pierre Rivière... y el mito de la uniformidad semántica de las ciencias jurídicas y sociales", en Revista de la Facultad de Derecho de la Universidad Complutense N 59, 1980, Madrid; y "José Ingenieros: el alienista, su loco y el delito", en Todo es historia $\mathrm{N}^{\circ} 173,1981$, Buenos Aires.

Mayer, Cristina (1978), “Historia del cuerpo y su represión”, en Punto de Vista N 4, pp. 16-17, Buenos Aires.

Melucci, Alberto (1994), "Asumir un compromiso: identidad y movilización en los movimientos sociales", en Zona Abierta $\mathrm{N}^{\circ} 69$, Madrid.

Moreno, Marcelo A. (1980), "La verdad y sus formas jurídicas, recoge brillantes conferencias de Michel Foucault", en Convicción, 11 de noviembre de 1980, p. 16, Buenos Aires.

Nun, José (1984), “La rebelión del coro”, en Punto de Vista $\mathrm{N}^{\circ}$ 20, pp. 6-11, Buenos Aires.

Punto de Vista (1981), N 12 , Buenos Aires.

Ídem (1983), № 17, Buenos Aires. Contiene: Léonard, J. "El historiador y el filósofo” y Foucault, M. "El polvo y la nube".

Sosnowski, Saúl (comp.) (1988), Represión y reconstrucción de una cultura: El caso argentino, Eudeba, Buenos Aires.

Terán, Oscar (1979), José Ingenieros. Antiimperialismo y nación, Siglo XXI, México.

Ídem (comp.) (1983), Michel Foucault: El discurso del poder, Folios, México.

Ídem (2008), Historia de las ideas en la Argentina, Siglo XXI, Buenos Aires.

Vezzetti, Hugo (1981), “Acerca del poder y la censura”, en Punto de Vista $\mathrm{N}^{\circ}$ 11, pp. 32-35, Buenos Aires.

Ídem (1982), “Ideología y psiquiatría: nacionalidad, raza, disciplina social”, en Punto de Vista $\mathrm{N}^{\circ} 15$, pp. 11-15, Buenos Aires.

\section{Entrevistas}

Dra. Susana Murillo, filósofa, 23/12/2008.

Dra. Lila Caimari, historiadora, 28/05/2009

Recibido: 15.02 .2012

Aceptado: 11.03.2012 